FACULdADE DE CIÊNCIAS ECONÔ MICAS DA UFRGS

MACROECONOMIA DO BRASIL PÓS-1994 LUIZ CARLOS BRESSER-PEREIRA

DESENVOLVIMENTO ECONOMMICO, PREFERÊNCIA PELA LIQUIDEZ E ACESSO BANCÁRIO: UM ESTUDO DE CASO DAS MESORREGIÓES DE MINAS GERAIS

MARCO CROCCO, CLAUDIO BARRA DE CASTRO, ANDERSON CAVALCANTE E VANESSA DA COSTA VAL

FRIEDMAN E O MONETARISMO: A VELHA TEORIA QUANTITATIVA DA MOEDA E A MODERNA ESCOLA MONETARISTA

GENTIL CORAZZAE RODRIGO L. KREMER

BOLLHAS RACIONAIS, CICLO DE PREÇOS DE ATIVOS E RACIONALIDADE LIMITADA: UMA AVALIACAOO CRITICA DOS MODELOS NEOCLÁSSICOS DE BOLHAS ESPECULATIVAS JOSÉ LUIS OREIRO

VULNERABILITY INDICATORS OF THE TWIN CRISES: THE EAST ASIAN EPISODE

TITO BELCHIOR SILVA MOREIRA

IMPACTOS POTENCIAIS DA NEGOCIAÇÃO DA ALCA SOBRE OS INVESTIMENTOS EXTERNOS EM SERVIÇOS PROFISSIONAIS NO BRASIL

MICHEL ALEXANDRE, OTAVIANO CANUTO E GILBERTO TADEU LIMA

TEORIA MARXISTA DO VALOR: UMA INTRODUÇẢO ALFREDO SAAD FILHO

UM ESTUDO EMPIRICO DOS CICLOS POLITICO. ECONOOMICOS NO BRASIL

ATHOS PRATES DA SILVEIRA PREUSSLER E MARCELO SAVINO PORTUGAL

RELENDO CHANDLER, WILLIAMSON E NORTH PARA ENTENDER O PROCESSO DE FORMACĀO DAS ESTRADAS DE FERRO NO BRASIL

JEFFERSON ANDRONIO RAMUNDO STADUTO

WEIMAR FREIRE DA ROCHA IR. E CLAIITON ATAIDES DE FREITAS

MATRIZ DE INSUMO-PRODUTO PARA A ECONOMIA TURISTICA BRASILEIRA: CONSTRUCCÃO E ANÁLISE DAS RELAÇÓES INTERSETORIAIS

FRANCISCO CASIMIRO FILHO E JOAQUIM JOSÉ MARTINS GUILHOTO

SEÇĀO ESPECIAL: AVALIAÇŌES INICIAIS DA POLITTICA ECONÓMICA DO GOVERNO LULA

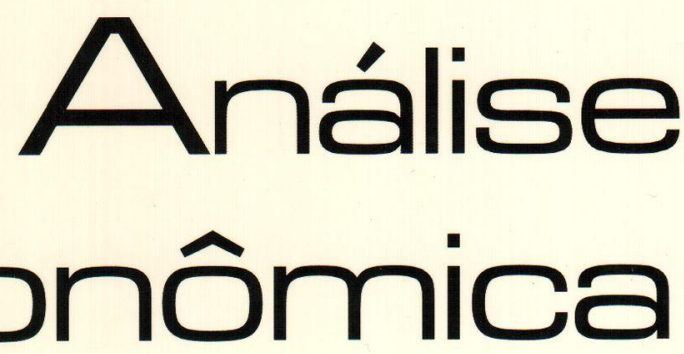


Universidade Federal do Rio Grande do Sul

Reitora: Profa. Wrana Maria Panizzi

Faculdade de Ciencias EConómicas

Diretora: Prof Pedro César Dutra Fonseca

Centro de Estudos e Pesquisas Economicas

Diretor: Prof. Gentil Corazza

Departamento de Ciéncias económicas

Chiefe: Prof. Ricardo Dathein

Curso de Pós. Graduação em Economia

Coordenador: Prof. Eduardo Pontual Ribeiro

Programa de Pós-Graduação em Desenvolvimento Rural

Coordenador: Prof. jalcione Almeida

CONSElHo EDITORIAL:

Carlos G. A. Mielitz Netto (UFRGS), Eduardo A. Maldonado Filho (UFRGS), Eduardo P. Ribeiro (UFRGS), Eleutério F. S. Prado (USP), Eugênio Lagemann (UFRGS), Fernando Cardim de Carvalho (UFRJ), Fernando Ferrari Filho (UFRGS), Fernando de Holanda Barbosa (FGV/RJ), Flávio Vasconcellos Comim (UFRGS), Gentil Corazza (UFRGS), Giácomo Balbinotto Netto (UFRGS), Gustavo Franco (PUC/RJ), Jan A. Kregel (UNCTAD), João Rogério Sanson (UFSC), Joaquim Pinto de Andrade (UnB), Jorge Paulo Araújo (UFRGS), Marcelo S. Portugal (UFRGS), Maria Alice Lahorgue (UFRGS), Paul Davidson (University of Tennessee), Paulo D. Waquil (UFRGS), Pedro C. D. Fonseca (UFRGS), Philip Arestis (Levy Economics Institut of Bard College), Roberto C. de Moraes (UFRGS), Ronald Otto Hillbrecht (UFRGS), Sabino da Silva Porto Jr. (UFRGS), Stefano Florissi (UFRGS) e Werner Baer (University of Illinois at UrbanaChampaign).

COMISSÃO EDITORIAL:

Eduardo Augusto Maldonado Filho, Fernando Ferrari Filho, Gentil Corazza, Marcelo Savino Portugal, Paulo Dabdab Waquil e Roberto Camps Moraes.

EDIroR: Prof. Fernando Ferrari Filho

Editor Adunnio: Prof. Gentil Corazza

SECRETÁrla: Clarissa Roncato Baldim

REVISÁO DE TEXTOS: Vanete Ricacheski

EDITORaÇão Eletrónica: Vanessa Hoffmann de Quadros

Fundador: Prof Antônio Carlos Santos Rosa

Os materiais publicados na revista Análise Econômica são da exclusiva responsabilidade dos autores. É permitida a reprodução total ou parcial dos trabalhos, desde que seja citada a fonte. Aceita-se permuta com revistas congêneres. Aceitam-se, também, livros para divulgação, elaboraçāo de resenhas e recensōes Toda correspondência, material para publicaçāo (vide normas na terceira capa), assinaturas e permutas devem ser dirigidos ao seguinte destinatário:

Análise Econômico

PROF FERNANDO FERRARI FILHO Revisła Análise Econômica - Av. João Pessoa, 52 CEP 90040-000 PORTO ALEGRE - RS, BRASL Telefones: (051) 316-3513 - Fax: (051) 316-3990 E-mail: rae@ufrgs.br

Ano 21, $n^{\circ} 39$, março, 2003 - Porto Alegre

Faculdade de Ciências Econômicas, UFRGS, 2003

Periodicidade semestral, março e setembro.

Tiragem: 500 exemplares

1. Teoria Econômica - Desenvolvimento Regional.

Economia Agrícola - Pesquisa Teórica e Aplicada -

Periódicos. I. Brasil

Faculdade de Ciências Econômicas,

Universidade Federal do Rio Grande do Sul 


\section{A Marcha da Insensatez: o programa econômico do Governo Lula}

Eduardo Maldonado Filho

\section{Introdução}

A eleição de Lula para a presidência da República foi inicialmente saudada por muitos, especialmente pelas forças populares, pela perspectiva de que, finalmente, seria possível dar início a um processo de mudança da sociedade brasileira - mudanças em direção a uma sociedade mais justa, solidária e economicamente dinâmica. A eleição de Lula mostrou que, na sociedade brasileira, a "esperança tinha vencido o medo". O programa apresentado durante a campanha eleitoral indicava que o novo governo adotaria uma nova política econômica e uma nova agenda de reformas, com vistas a realizar uma transição entre "o que temos hoje e aquilo que a sociedade reivindica": um novo modelo de desenvolvimento, tendo como objetivos centrais o crescimento econômico, a geração de empregos, a maior participação popular nos processos de decisão, em especial na área econômica, e de crescente justiça social.

No entanto, se, por um lado, as medidas iniciais de política econômica e as propostas de reformas institucionais apresentadas pelo governo Lula rapidamente geravam ansiedade e frustração entre seus apoiadores, por outro lado, essas medidas traziam euforia e aprovação entre as forças conservadoras que haviam sido derrotadas eleitoralmente. Os "mercados", o FMI e o governo americano não se cansam de elogiar a responsabilidade e competência do novo governo nas questões econômicas. Afinal, eles têm argumentado há já algum tempo que não existem outras alternativas viáveis às reformas neoliberais e à adoção de políticas macroeconômicas "responsáveis".

Existe já um reconhecimento na sociedade brasileira de que a política econômica e a agenda de reformas estruturais que estão

${ }^{1}$ Professor do Departamento de Economia e do Programa de Pós-graduação em Economia da UFRGS. Agradeço ao Alberto Nogueira pelos comentários e sugestōes à versão preliminar deste artigo. 
sendo implementadas pelo Governo Lula são muito diferentes daquelas propostas defendidas historicamente pelo PT. Esta "guinada histórica”, segundo lideranças petistas, teria ocorrido durante o processo eleitoral, com a divulgação, em 22 de junho de 2002, da Carta ao Povo Brasileiro pelo candidato Lula. $\mathrm{Na}$ Carta, Lula teria apresentado as linhas gerais da política econômica e das reformas estruturais que estão sendo implementadas pelo seu governo. O Ministro da Fazenda, Antônio Palocci, afirmou recentemente que "as teses foram defendidas durante a campanha e praticamos exatamente o que estava escrito" (Correio do Povo, 22/jun./2003, p. 2). Não restam dúvidas de que qualquer governo eleito tem a obrigação de implementar as teses defendidas durante a campanha eleitoral, mas a questão é justamente saber se é isto que está acontecendo. A política econômica defendida pelo candidato Lula durante o período eleitoral representou de fato uma "guinada histórica" do PT, conforme tem sido defendido pelo governo e repercutido por muitos veículos de comunicação? A agenda de reformas do governo Lula se constitui no "necessário período de transição para o novo modelo"? Se as teses defendidas na campanha são diferentes das ações que estão sendo implementadas pelo governo, ao contrário do que afirma o Ministro Palocci, qual é, então, o embasamento econômico desta agenda? Quais são os resultados econômicos - crescimento do produto, do emprego e redução das desigualdades sociais e dos níveis de pobreza - que podemos esperar, tendo em vista outras experiências históricas, da implantação deste modelo pelo Governo Lula? A agenda econômica do Governo Lula é consistente com seus objetivos de retomada do crescimento sustentável da economia brasileira com inclusão social?

O artigo está organizado em cinco seções. A segunda seção trata do diagnóstico dos entraves ao crescimento econômico contido nos documentos do PT, apresentados durante a campanha eleitoral e, na terceira seção, se explicita qual seria a agenda econômica necessária para implementação de um modelo de desenvolvimento alternativo, capaz de propiciar a retomada do crescimento econômico com inclusão social. Na quarta seção, analisamos o argumento econômico que embasa a política econômica e as reformas estruturais que estão sendo implementadas pelo Governo Lula. Finalmente, na última seção, apresentamos as principais conclusões da análise. 


\section{O Programa do Econômico do PT}

O Partido dos Trabalhadores apresentou à sociedade brasileira, durante a campanha eleitoral, três documentos explicitando suas propostas para governar o Brasil, a saber: (i) Concepção e Diretrizes do Programa de Governo do PT para o Brasil (março de 2002), que foi aprovado no XII Encontro Nacional do PT realizado em Recife em dezembro de 2001; (ii) Carta ao Povo Brasileiro (Silva, 2002) e (iii) Programa de Governo 2002 da Coligação Lula Presidente, Um Brasil para Todos (2002). Uma análise detalhada desses documentos mostra que eles basicamente reafirmam muitas das proposições históricas defendidas pelo $\mathrm{PT}^{2}$. Em particular, Borges Neto (2002, p. 11) mostra que "Levando em conta o programa Um Brasil para Todos no seu conjunto, podemos concluir que ele representou um movimento na direção de maior moderação, mas que isto não aconteceu tanto por ele defender uma concepção diferente do texto das Diretrizes, e sim por não explicitar algumas das conseqüências mais 'radicais' da concepção defendida. A própria idéia de 'transição' é vinculada à busca de um modelo de desenvolvimento muito diferente daquele do governo de F. H. Cardoso".

O programa de governo apresentado à sociedade brasileira durante a campanha eleitoral parte de uma visão crítica do modelo neoliberal que estava sendo implementado pelo governo FHC e assume o compromisso de construir um modelo de desenvolvimento alternativo, capaz de promover o crescimento econômico, a justiça social e que seja ecologicamente sustentável. No entanto, existe o reconhecimento de que para a construção desse novo modelo de desenvolvimento "será necessária uma lúcida e criteriosa transição entre o que temos hoje e aquilo que a sociedade reivindica" (Silva, 2002).

Vejamos então, de uma forma breve, o argumento econômico básico que está presente nos documentos apresentados pelo PT durante a campanha eleitoral:

I. A partir de uma avaliação crítica do modelo neoliberal implantado no Brasil durante os governos Collor e FHC, conclui-se que o mesmo não foi capaz de gerar crescimento econômico, empregos e que tem gerado um crescente aumento da exclusão social.

II. Diante deste fracasso, o programa do PT reafirma a necessidade de se romper com o modelo neoliberal. O entendimento é que

${ }^{2}$ Para uma análise detalhada dessas propostas, ver Borges Neto (2003). 
a continuidade na implementação desse modelo vai levar à estagnação econômica, podendo mesmo resultar numa grave crise.

III. A mudança do modelo atual para o novo modelo de desenvolvimento requer um período de transição, durante o qual as políticas econômicas e as reformas necessárias para a construção do novo modelo devem ser implementadas de forma gradual e através de uma ampla negociação nacional, com o respeito aos contratos e obrigações já assumidos pelo país.

IV. O principal entrave à retomada do crescimento econômico está na vulnerabilidade externa; ou seja, no fato de a economia brasileira apresentar, por decorrência do elevado endividamento externo e dos significativos déficits em transações correntes, um desequilibrio estrutural de suas contas externas, o que a torna cronicamente dependente dos fluxos de capitais externos - e não no desequilíbrio das contas públicas, conforme a avaliação da área econômica do governo FHC, dos investidores e do FMI. Por isso, os objetivos das políticas macroeconômicas e das reformas estruturais de um Governo Lula estariam direcionados, prioritariamente, para a superação da vulnerabilidade externa.

V. Na avaliaçāo dos formuladores do programa de governo, a liberalização financeira e a do comércio externo, combinada com a sobrevalorização cambial do período 1994-98 (o chamado "populismo cambial"), teriam acentuado, ainda mais, a tradicional vulnerabilidade externa da economia brasileira. Esta avaliação é importante porque ela implica, necessariamente, a proposição de que é imprescindível estabelecer um maior controle sobre o movimento de capitais.

VI. Portanto, a partir deste diagnóstico sobre os principais entraves à retomada do crescimento econômico, o objetivo central da política econômica e das reformas estruturais para a construção de um outro modelo de desenvolvimento fica claramente estabelecido, a saber: redução significativa da dependência da economia brasileira do fluxo de capitais externos, obtendo, com isso, a recuperação do controle das contas externas. Em outras palavras, o programa de governo do PT afirma que a retomada do crescimento econômico passa pela implementação de políticas econômicas e de reformas estruturais que promovam a elevação das exportações, a substituição de importações (permitindo, assim, que se crie um amplo mercado interno de massas) e, também, que resultem na redução do déficit das transaçōes correntes do balanço de pagamentos. 
VII. Finalmente, o programa do PT reconhece a importância de se obter um equilibrio das contas públicas. Mas este "ajuste estrutural das contas públicas" só vai ser possível através da redução da vulnerabilidade externa, o que vai permitir, por sua vez, a redução das taxas de juros. Ou seja, na visão dos formuladores do programa do PT, o principal determinante do desequilíbrio fiscal está relacionado com as elevadíssimas taxas de juros, cujas causas decorrem da vulnerabilidade externa da economia brasileira. Mais ainda, a visão neoliberal de que a não obtenção de um "ajuste fiscal definitivo" se constitui no principal entrave ao crescimento econômico é repudiada, pois levaria, na verdade, a uma nova armadilha: controle inflacionário com estagnação econômica.

\section{As Medidas Necessárias para Implementar o Programa do PT}

As principais medidas para implementar o programa econômico do PT seriam as seguintes:

I. política monetária de redução das taxas de juros

tendo em vista a grande dependência da economia brasileira em relação aos fluxos de capitais externos, esta política monetária precisaria ser acompanhada por medidas que dessem ao BACEN um maior grau de controle da conta de capitais do balanço de pagamentos - ou seja, seria necessária a implantação de controles preventivos sobre o movimento de capitais - e por medidas que reduzissem o déficit das transações correntes do balanço de pagamentos;

II. política fiscal continuaria, num primeiro momento, restritiva

conforme visto acima, o governo Lula continuaria com a política fiscal comprometida com a geração de superávits primários com vistas a evitar que a relação dívida pública/PIB aumentasse. Mas, assim que as condições das contas externas e da dívida pública melhorassem, a política fiscal também poderia tornar-se expansionista;

III. política agressiva de promoção das exportações e de substituição das importações

além de uma política ativa de promoção das exportações, a política cambial também teria um papel fundamental para atingir o objetivo de elevar de forma significativa o saldo da balança comer- 
cial. Adoção de uma política industrial de incentivo aos setores exportadores e aos setores de substituição de importações;

IV. reformas estruturais

as reformas institucionais necessárias para a construção do novo modelo de desenvolvimento seriam aquelas capazes de promover o crescimento econômico e as exportaçōes e de gerar maior eqüidade social. Em outras palavras, seriam realizadas aquelas reformas estruturais que "democratizem e modernizem o país, tornando-o mais justo, eficiente e, ao mesmo tempo, mais competitivo no mercado internacional" (Silva, 2002).

Finalmente, cabe ressaltar a crítica apresentada pelo programa de governo do PT à estratégia de que o ajuste fiscal seja o pressuposto para a retomada do crescimento econômico sustentável:

A questāo chave para o País é voltar a crescer com equilíbrio em todos os ramos de atividade, na agricultura, na indústria, no comércio e nos serviços. A volta do crescimento é o remédio para impedir que se estabeleça um círculo vicioso entre juros altos, instabilidade cambial e aumento da dívida pública em proporção ao PIB. O atual governo estabeleceu um equilíbrio fiscal precário, criando dificuldades para a retomada do desenvolvimento. $\mathrm{O}$ resultado é que a âncora fiscal que procura evitar o crescimento acelerado da dívida pública interna, pela via dos superávits primários, exige um esforço enorme de todos os brasileiros, afetando especialmente a viabilidade dos programas sociais do poder público. A âncora fiscal, ao ter como um de seus fundamentos uma carga tributária amplamente baseada em impostos cumulativos, acaba tendo um efeito limitador da atividade econômica e das exportações. Entretanto, esta é, do ponto de vista objetivo, a realidade que o futuro governo vai herdar e que não poderá reverter num passe de mágica. $\mathrm{O}$ problema de fundo é que o atual governo colocou o Brasil num impasse financeiro, que nos obriga, com freqüência, a contrair empréstimos novos para pagar empréstimos velhos. A superação desses obstáculos à retomada do crescimento acontecerá por meio de uma lúcida e criteriosa transição entre o que temos hoje e aquilo que a sociedade reivindica (Um Brasil para Todos p. 10).

\section{Política Econômica e Reformas Estruturais no Governo Lula: a recuperação da "Agenda Perdida"}

A análise realizada anteriormente permite concluir que a agenda econômica que está sendo implementada pelo Governo Lula di- 
fere daquela defendida no processo eleitoral. A questão, portanto, é saber qual o diagnóstico que orienta a atual política econômica e de reformas estruturais. Felizmente, é possivel responder a esta pergunta de uma forma objetiva, já que o Ministério da Fazenda publicou o documento Politica Econômica e Reformas Estruturais (2003), onde são apresentadas "as prioridades da agenda econômica do Ministério da Fazenda para este ano e aponta[-se] como estas prioridades se inserem no contexto de mudança do País".

Segundo o documento do Ministério da Fazenda, as três idéias essenciais do programa de governo apresentadas durante o processo eleitoral foram: (i) a retomada do crescimento em bases sustentáveis; (ii) período de transição durante o qual seria realizado "um processo de ajuste das condições macroeconômicas e a implementação de reformas estruturais" (p. 4); e (iii) a inclusão social como eixo central do projeto de desenvolvimento. O documento também afirma que, no programa de governo do PT, devem ser considerados inseparáveis do projeto de desenvolvimento os seguintes aspectos: "[i] a retomada do crescimento econômico em bases sustentáveis, [ii] o fortalecimento das instituiçōes essenciais à participação social e ao adequado funcionamento dos mercados ${ }^{3}$ e [iii] a melhoria da distribuição de renda, que deve ser compatível com a igualdade de acesso dos diversos grupos sociais aos bens e serviços básicos, como saúde e educação, assim como oportunidades de emprego" (p. 4-5).

Os problemas centrais apresentados pela economia brasileira - baixas taxas de crescimento econômico e elevado grau de concentração de renda - estão associados aos seus problemas estruturais, sendo o principal deles o desequilíbrio das contas públicas. Este desequilíbrio, por sua vez, implica altas taxas de inflaçāo, ou elevação da relação dívida/PIB. Ambos os resultados têm efeitos ne-

\footnotetext{
${ }^{3}$ A afirmação de que o "fortalecimento das instituiçóes essenciais ao adequado funcionamento dos mercados" se constitua num dos aspectos inseparáveis do projeto de desenvolvimento defendido pelo PT não deixa de ser surpreendente, mesmo considerando o processo de moderação que vem ocorrendo no PT mais recentemente. No entanto, uma busca meticulosa nos dois documentos da campanha eleitoral referidos pelo trabalho do Ministério da Fazenda mostra que não existe qualquer defesa, nem mesmo qualquer indicação indireta de apoio, de que, na visão do PT, o "adequado funcionamento dos mercados" se constitua num dos aspectos inseparáveis do projeto de desenvolvimento proposto para o Brasil. Dada a relevância do tema, seria importante que os formuladores da política econômica do Governo Lula explicitassem as razôes que os levam a acreditar que o "adequado funcionamento dos mercados" se constitua num dos pilares de um projeto de desenvolvimento que tem como eixo a inclusão social e que está baseado numa crescente democratização da vida econômica, social e política.
} 
gativos sobre o crescimento econômico e a distribuição de renda. Coerentemente com este diagnóstico, o documento propõe que, neste período inicial de transição, sejam assentadas as bases (i.e.., sejam implementadas as reformas estruturais) que vão permitir a retomada do crescimento econômico; ou seja, sejam realizadas aquelas "reformas necessárias" à obtenção do equilíbrio estrutural das contas públicas.

Portanto, segundo o documento do Ministério da Fazenda, os principais entraves à retomada do crescimento econômico em bases sustentáveis encontram-se no desequilíbrio das contas públicas e no funcionamento inadequado dos mercados. A partir deste diagnóstico, o documento define como objetivos principais para a politica econômica a obtenção de um ajuste fiscal definitivo e a implementação das reformas estruturais que garantam o funcionamento adequado das instituições e dos mercados. Além dessas medidas essenciais, o Ministério da Fazenda também propõe a adoção de algumas políticas econômicas específicas que podem auxiliar na retomada do crescimento econômico (tais como, incentivo ao desenvolvimento tecnológico e à inovaçāo, redução dos incentivos à informalidade no mercado de trabalho, redução dos custos de logística e transporte, unificação e coordenação das políticas de comércio exterior e investimentos em infra-estrutura).

Cabe destacar, finalmente, a proposta de reforma do mercado de crédito. O objetivo dessa reforma é o de modificar o marco institucional de forma a permitir a expansão deste mercado, trazendo efeitos positivos tanto sobre o bem-estar das famílias quanto sobre a aceleração das taxas de crescimento econômico. Adicionalmente, o documento argumenta que a expansão do mercado de crédito aumentaria a efetividade da política monetária. A reforma a ser proposta prevê a aprovação de uma nova lei de falências "cujo objetivo seja permitir tanto a redução dos spreads bancários, quanto evitar a destruição dos empregos e ativos de empresas em graves dificuldades financeiras. Além disso, também são propostas diversas medidas com o objetivo de fortalecer o sistema de garantias existentes que permitirão a redução dos spreads bancários" (p. 14). A aprovação desta lei se constitui num "projeto prioritário na agenda de reformas" (p. 89) e sua aprovação no Congresso Nacional ainda neste ano faz parte dos compromissos do Governo Lula com o FMI.

Como foi visto acima, a agenda econômica proposta pela Coligação Lula Presidente durante a campanha eleitoral teve como base 
o diagnóstico de que o principal entrave à retomada do crescimento econômico estava relacionado com a vulnerabilidade externa da economia brasileira, e não com o desequilíbrio das contas públicas. Por decorrência deste diagnóstico, os objetivos prioritários das políticas macroeconômicas e das reformas estruturais estariam direcionados para a superação da vulnerabilidade externa. Portanto, a base das políticas e reformas econômicas que estão sendo implementadas pelo Governo Lula não são aquelas dos documentos divulgados durante a campanha eleitoral. Na verdade, o programa econômico do Governo Lula tem como base o documento elaborado por importantes economistas liberais e denominado de "A Agenda Perdida: diagnósticos e propostas para a retomada do crescimento com maior justiça social" ${ }^{4}$.

\section{Comentários Finais}

Durante a campanha eleitoral, Lula reafirmou muitos dos compromissos históricos do PT, em especial com a retomada do crescimento econômico, com a criação de empregos e com a implementação das mudanças necessárias para construção de um outro modelo de desenvolvimento, baseado no dinamismo econômico e na justiça social. No discurso de posse, o Presidente Lula reafirmou o compromisso de seu governo com o crescimento econômico e com a construção de um outro modelo de desenvolvimento. No entanto, a política econômica e a agenda de reformas estruturais que estão sendo implementadas pelo seu governo, como foi visto acima, são de continuidade em relação ao Governos Collor e FHC - e não de mudança de rumo.

O principal obstáculo à retomada do crescimento econômico, segundo o diagnóstico apresentado nos documentos da campanha eleitoral, decorria da vulnerabilidade externa da economia brasileira. Mas agora no governo, conforme foi mostrado nesse artigo, o diagnóstico é diferente: os principais entraves à retomada do crescimento econômico em bases sustentáveis são atribuídos ao desequilíbrio das contas públicas e ao funcionamento inadequado dos mercados. A mudança de diagnóstico implica, evidentemente,

${ }^{4}$ Curiosamente, apesar de claramente servir de base para a elaboração do docurnento do Ministro da Fazenda, a "Agenda Perdida" não consta das referências bibliográficas do mesmo. 
mudanças na política macroeconômica e na agenda de reformas. Infelizmente, o documento do Ministério da Fazenda não explicita as razões que levaram o Governo Lula a esta drástica mudança de diagnóstico e, conseqüentemente, de implementação das políticas macroeconômicas e das reformas estruturais. Certamente, a equipe econômica do Governo Lula irá expor, em breve, as razões dessa mudança de rumo.

A análise realizada neste artigo permite descartar os seguintes argumentos que têm sido apresentados no debate público: (i) que o programa econômico proposto durante o período eleitoral representou uma "guinada histórica" do PT; (ii) que a política econômica atual representa apenas a implementação das teses defendidas durante a campanha eleitoral e (iii) que a agenda de reformas do governo Lula se constitui no "necessário período de transição para o novo modelo". Ao contrário, a política econômica e as reformas estruturais que estão sendo implementadas pelo Governo Lula implicam, na verdade, a continuidade da consolidação do modelo neoliberal no Brasil.

Apesar dessa radical mudança nos rumos da política econômica (ou justamente por conseqüência dessa revisão da interpretação sobre os problemas da economia brasileira), será possível ao Governo Lula atingir os objetivos propostos: retomada do crescimento econômico, redução significativa das taxas de desemprego e redução das desigualdades sociais e dos níveis de pobreza? Ou seja, a agenda econômica do Governo Lula é consistente com seus objetivos de retomada do crescimento da economia brasileira com inclusão social?

A partir da farta evidência empírica sobre o desempenho econômico e social dos países que implementaram as reformas neoliberais, podemos afirmar que o Governo Lula não será capaz de atingir seus objetivos ${ }^{5}$. Ao contrário, podemos esperar - a exemplo da África do Sul - que o Governo Lula terá sucesso no controle do processo inflacionário, mas esse sucesso será obtido ao custo de baixas taxas de crescimento econômico, manutenção ou elevação das taxas de desemprego, aumento da concentração da renda e da riqueza, aumento da pobreza e recorrentes crises cambiais.

5 Essa afirmação, baseada na história e na evidência empírica internacional (ver Maldonado Filho, 2003b), é corroborada pelo estudo de Gonçalves (2003) para a economia brasileira. 
Na nossa opinião, o programa de governo proposto pelo P'T durante o período eleitoral oferece uma base consistente para a implementação de políticas macroeconômicas e de reformas estruturais que seriam capazes de promover a retomada do crescimento econômico com inclusão social. Existem diversas contribuições importantes para a construção dessa nova estratégia de desenvolvimento econômico e social ${ }^{6}$, mas que, infelizmente, foram abandonadas em favor de se dar continuidade à consolidação de um modelo que vem sendo implantado no Brasil desde o Governo Collor. Não deixa de ser surpreendente que nesse momento histórico quando os efeitos perversos para o desenvolvimento e a inclusão social que resultam da implantação do modelo neoliberal já são bem conhecidos - , o Partido dos Trabalhadores, numa verdadeira "marcha da insensatez", resolva adotar como sua esta estratégia fracassada.

\section{Referências bibliográficas}

BATISTA Jr. (2002).Vulnerabilidade Externa da Economia Brasileira. Estudos Avançados, $16, \mathrm{n}^{\circ} 45$.

BORGES NETO, J. M. (2003). Um Governo Contraditório. Revista da SEP, $\mathrm{n}^{\circ} 12$, junho.

GALBRAITH, J. K. (1983). Moeda: de onde veio, para onde foi. São Paulo: Livraria Pioneira Editora, $2^{\text {a }}$ edição.

GONÇALVES, R. (2003). Política Econômica e Macrocenários Nacionais: 20032006. Argumento, $\mathrm{n}^{\circ}$ 3, Maio.

LISBOA, M. de B. (2002). A Agenda Perdida: diagnósticos e propostas para a retomada do crescimento com maior justiça social. Mimeo. Rio de Janeiro, setembro. MALDONADO FILHO, E. (2003a). Autonomia do Banco Central, Democracia e Desenvolviment. Departamento de Ciências Econômicas/UFRGS, Texto para Discussão n 10/2003.

MALDONADO FILHO, E. (2003b). O Programa do PT e as 'Reformas Necessárias'. Mirneo.

MINISTÉRIO DA FAZENDA (2003). Política Econômica e Reformas Estruturais. Disponivel no site http://www.fazenda.gov.br/

PARTIDO DOS TRABALHADORES (2002). Concepção e Diretrizes do Programa

${ }^{6}$ Ver, por exemplo, Batista Jr. (2002) e Saad Filho (2003). 
de Governo do PT para o Brasil, XII Encontro Nacional do PT, dezembro de 2001. Publicação do Diretório Nacional do PT, março de 2003. Disponível em http:// www.lula.org.br/obrasil/documentos.asp.

PARTIDO DOS TRABALHADORES (2002). Programa de Governo 2002 da Coligaçāo Lula Presidente, Um Brasil para Todos. Disponivel em http://www.lula.org.br/ obrasil/documentos.asp.

SAAD FILHO, A. (2003). Democratic and Pro-Poor Economic Strategies for Developing Countries: an overview.

Silva, L. I. L. Da (2002). Carta ao Povo Brasileiro. Disponível em hittp:/ www.lula.org.br/obrasil/documentos.asp. 